\title{
Hypoxemia Adds to the CURB-65 Pneumonia Severity Score in Hospitalized Patients With Mild Pneumonia
}

\author{
Francisco Sanz MD PhD, Marcos I Restrepo MD MSc, Estrella Fernández MD PhD, \\ Eric M Mortensen MD MSc, María Carmen Aguar MD PhD, Ángela Cervera MD, \\ Eusebi Chiner MD PhD, and Jose Blanquer MD PhD; the \\ Neumonía Adquirida en la Comunidad de la Comunidad Valenciana Study Group
}

\begin{abstract}
BACKGROUND: Hypoxemia may influence the prognosis of patients with mild pneumonia, regardless of the initial CURB-65 score (confusion, blood urea nitrogen $>20 \mathrm{mg} / \mathrm{dL}$, respiratory rate $>30$ breaths/min, blood pressure $<90 / 60 \mathrm{~mm} \mathrm{Hg}$, and age $\geq 65 \mathrm{y}$ ). OBJECTIVE: To determine the risk factors associated with hypoxemia and the influence of hypoxemia on clinical outcomes in hospitalized patients with mild pneumonia. METHODS: We performed a multicenter prospective cohort study of 585 consecutive hospitalized patients with mild pneumonia (CURB-65 groups 0 and 1). We stratified the patients according to the presence of hypoxemia, defined as a $\mathbf{P}_{\mathrm{aO}_{2}}$ / $\mathrm{F}_{\mathrm{IO}_{2}}<300 \mathrm{~mm} \mathrm{Hg}$ on admission. We assessed the risk factors associated with hypoxemia, hypoxemia's influence on the course of pneumonia, and clinical outcomes (mortality, hospital stay, and need for intensive care unit admission), with multivariable regression. RESULTS: Fifty percent of the patients (294 cases) had hypoxemia on admission. The risk factors independently associated with hypoxemia were: bilateral radiological involvement (odds ratio 2.8, $95 \%$ CI 1.1-7.5), history of COPD (odds ratio 2.5, 95\% CI 1.4-4.3), and hypoalbuminemia (odds ratio 2.0, 95\% CI 1.1-3.5). The hypoxemic patients had longer hospital stay, higher intensive care unit admission rate, higher rate of severe sepsis, and higher mortality than the non-hypoxemic patients. CONCLUSIONS: Hypoxemia in patients with mild pneumonia is independently associated with several adverse clinical and radiological variables, and the hypoxemic patients had worse clinical outcomes than the non-hypoxemic patients. Therefore, additional attention should be paid to the presence of hypoxemia, regardless of a low CURB-65 score. Key words: hypoxemia; prognosis; pneumonia; CURB-65; outcomes; oxygenation. [Respir Care 2011;56(5):612-618. (C) 2011 Daedalus Enterprises]
\end{abstract}

\footnotetext{
Francisco Sanz MD PhD is affiliated with Servicio de Neumología. Consorci Hospital General, Universitari de Valencia, Spain. Marcos I Restrepo MD MSc is affiliated with the Department of Pulmonary and Critical Care Medicine, University of Texas Health Science Center, San Antonio, Texas, and with the Veterans Evidence Based Research Dissemination and Implementation Center (VERDICT), South Texas Veterans Health Care System, San Antonio, Texas. Estrella Fernández MD $\mathrm{PhD}$ and Ángela Cervera MD are affiliated with Servicio de Neumología, Hospital Universitario Doctor Peset de Valencia, Spain. Eric M Mortensen MD MSc is affiliated with VERDICT, South Texas Veterans Health Care System, San Antonio, Texas. María Carmen Aguar MD PhD is affiliated with Servicio de Neumología, Hospital Arnau de Vilanova, Valencia, Spain. Eusebi Chiner MD PhD is affiliated with Servicio de Neumología, Hospital de Sant Joan, Alacant, Spain. Jose Blanquer MD PhD is affiliated with Servicio de Medicina Intensiva, Hospital Clínic Universitari de Valencia, Spain. The views expressed in this paper are those of the authors and do not represent the views of the United States Department of Veterans Affairs
}

\begin{abstract}
Dr Restrepo was partly supported by a Department of Veteran Affairs Veterans Integrated Service Network 17 new faculty grant, by National Institutes of Health grant KL2 RR025766, and by Clinical and Translational Science Award KL2 RR025766/VISN-17. Dr Restrepo has disclosed relationships with Johnson \& Johnson, CR Bard, Pfizer, Covidien, Ortho McNeil-Janssen, Whyeth, Theravan. Dr Mortensen EM has disclosed a relationship with the United States National Institutes of Health. The other authors have disclosed no conflicts of interest. The organizations that supported this research had no role in conducting the study or preparing, reviewing, or approving this paper.
\end{abstract}

Correspondence: Francisco Sanz MD PhD, Servicio de Neumología, Consorci Hospital General Universitari de Valencia, Av Tres Cruces 2, 46014 Valencia, Spain. E-mail: sanz_fraher@gva.es.

DOI: $10.4187 /$ respcare.00853 


\section{Hypoxemia Adds to the CURB-65 Pneumonia Severity Score}

\section{Introduction}

Community-acquired pneumonia is an important cause of morbidity and mortality worldwide. ${ }^{1-3}$ The spectrum of pneumonia severity ranges from mild, which can frequently be treated on an out-patient basis, to very severe, with multiple complications and high mortality, so determining the pneumonia severity is key in pneumonia management. Pneumonia severity scores assess the risk of death and assist in deciding where to admit and treat the patient. ${ }^{4-7}$

The 2007 American Thoracic Society/Infectious Diseases Society of America guidelines on community-acquired pneumonia recommend the use of the CURB-65 assessment instrument (confusion, blood urea nitrogen $>20 \mathrm{mg} / \mathrm{dL}$, respiratory rate $>30$ breaths $/ \mathrm{min}$, blood pressure $<90 / 60 \mathrm{~mm} \mathrm{Hg}$, and age $\geq 65 \mathrm{y}$ ) or the Pneumonia Severity Index to stratify pneumonia severity. ${ }^{6,8}$ The simplicity of the CURB-65 score (5 variables) favors its use over the more complex Pneumonia Severity Index (20 variables). ${ }^{5,9}$ The CURB-65 and the simplified CRB-65 (which excludes blood urea nitrogen) have been extensively validated, and give results comparable to those of the Pneumonia Severity Index. ${ }^{9-11}$ CURB-65 has a high negative predictive value, and it has been suggested that when none or only one of the CURB-65 risk factors is present, the pneumonia should be classified as mild and the patient can be safely treated at home with low likelihood of adverse events, so there is no need for hospitalization, intensive care unit (ICU) admission, or mechanical ventilation. The mortality in patients with mild pneumonia is reportedly $<1 \%$. $^{4-6,12}$

Therefore, we focused on patients with CURB-65 scores of 0 or 1 (mild pneumonia) because of their low risk of death, to determine the impact of low $\mathrm{P}_{\mathrm{aO}_{2}} / \mathrm{F}_{\mathrm{IO}_{2}} \cdot{ }^{4}$ Low $\mathrm{P}_{\mathrm{aO}_{2}} / \mathrm{F}_{\mathrm{IO}_{2}}$ in patients with pneumonia is one of the principal pathophysiologic signs of lung impairment and is associated with poor clinical outcomes in patients with severe pneumonia. ${ }^{13}$ Despite the extent of data available regarding the importance of hypoxemia in patients with severe community-acquired pneumonia, there is limited information on the presence of hypoxemia and its impact on outcomes in patients with mild pneumonia. We hypothesized that adding hypoxemia to the CURB-65 assessment might help identify patients at risk of dying, who will need ICU care, and who are more likely to have a longer hospital stay. Therefore, our aims were to determine the risk factors associated with hypoxemia in hospitalized patients with mild pneumonia (CURB-65 score of 0 or 1 ), and to assess the influence of hypoxemia on mortality, hospital stay, and need for ICU admission in those patients.

\section{Methods}

We carried out a prospective multicenter cohort study at 10 hospitals in the Valencia region of Spain. We included hospitalized patients with community-acquired pneumonia, over a one-year period, October 2003 to October 2004. The local ethics committees approved the study, and all of the subjects provided informed consent.

The inclusion criteria were $\geq 18$ years old, with mild (CURB-65 score 0 or 1) community-acquired pneumonia (defined as at least two of the following symptoms: fever, chest pain, dyspnea, coughing, and expectoration), and with a new alveolar infiltrate on chest radiograph. The exclusion criteria were nosocomial pneumonia (defined as pneumonia that developed $\geq 48 \mathrm{~h}$ after hospital admission or within 14 days of hospital discharge); healthcare-associated pneumonia, which included patients in long-term care facilities, who had recent hospitalization, or who had contact with the healthcare environment (eg, therapy in a dialysis center); and immunosuppression (eg, human immunodeficiency virus, hematological malignancy, active chemotherapy, or prolonged corticosteroids [over $20 \mathrm{mg}$ prednisone per day for at least 3 weeks]).

Demographic data collected included age, sex, smoking history, alcoholism (consumption of over $80 \mathrm{~g} / \mathrm{d}$ ), and illicit drug use. Comorbid conditions recorded included previous diagnosis of COPD (per the criteria of the Global Initiative for Chronic Obstructive Lung Disease ${ }^{14}$ ), chronic renal failure, congestive heart failure, cerebrovascular disease, diabetes mellitus, chronic liver disease (viral, toxic, hepatic cirrhosis), and neoplasia. Recorded clinical signs and symptoms were: cough, expectoration, pleuritic chest pain, dyspnea, confusion, cyanosis, temperature, tachypnea (respiratory rate $\geq 30$ breaths/min), heart rate, and arterial blood pressure on hospital admission. Radiological findings recorded were unilateral or bilateral chest radiograph involvement. Basic biochemical data collected at admission included serum glucose, albumin, blood urea nitrogen, creatinine, sodium, aspartate aminotransferase, alanine aminotransferase, leukocyte count, and arterial blood gases ( $\mathrm{pH}, \mathrm{P}_{\mathrm{aO}}$, and $\mathrm{P}_{\mathrm{aCO}_{2}}$ ). Hypoalbuminemia was defined as a serum albumin of $<3.5 \mathrm{~g} / \mathrm{dL}$.

\section{$\mathrm{P}_{\mathrm{aO}} / \mathrm{F}_{\mathrm{IO}_{2}}$ Calculation}

We measured $\mathrm{S}_{\mathrm{pO}_{2}}$ on arrival in the emergency department. Supplemental oxygen was via air-entrainment mask in all cases, titrated to an $\mathrm{S}_{\mathrm{pO}_{2}}$ of $>90 \%$. In all patients who received oxygen before emergency department admission, the oxygen administration method was changed to air-entrainment mask, then we obtained arterial blood gas values, including $\mathrm{P}_{\mathrm{aO}_{2}}$. We recorded the $\mathrm{F}_{\mathrm{IO}_{2}}$ noted in the emergency department medical chart. We dichoto- 
mized hypoxemia into $\mathrm{P}_{\mathrm{aO}_{2}} / \mathrm{F}_{\mathrm{IO}_{2}}<300 \mathrm{~mm} \mathrm{Hg}$ and $>300 \mathrm{~mm} \mathrm{Hg} .{ }^{15}$

\section{Pneumonia Severity Assessment}

We used the CURB-65 instrument to assess pneumonia severity. ${ }^{10}$ CURB- 65 has been validated for predicting mortality in patients with community-acquired pneumonia. The absence of any of the CURB-65 criteria (confusion, blood urea nitrogen $>20 \mathrm{mg} / \mathrm{dL}$, respiratory rate $>30$ breaths/ min, blood pressure $<90 / 60 \mathrm{~mm} \mathrm{Hg}$, and age $\geq 65 \mathrm{y}$ ) or the presence of at least one of the criteria classifies the patient into the mild pneumonia/low-risk patient category. ${ }^{4}$ CURB-65 scores $\geq 2$ (maximum 5) indicate moderate to severe pneumonia, which have higher mortality and more clinical complications than mild pneumonia. We excluded patients with CURB-65 scores above 1.4

\section{Microbiological Assay}

The following microbiological tests were carried out to ascertain the etiology of the community-acquired pneumonia:

- Two sets of blood cultures

- Urinary antigen test for Streptococcus pneumoniae and Legionella pneumophila, via immunochromatographic assay (Binax NOW urinary antigen test, Binax, Portland, Maine)

- Paired sera (4-6-week intervals) for antibody determination of Chlamydophila pneumoniae, Mycoplasma pneumoniae, Legionella pneumophila and respiratory viruses, via complement fixation, indirect immunofluorescence, and enzyme-linked immunosorbent assay (ELISA)

\section{Outcomes}

Our primary outcome was hypoxemia. Secondary outcomes included the need for ICU admission, the need for mechanical ventilation, the presence of severe sepsis (defined as a systolic blood pressure of $<90 \mathrm{~mm} \mathrm{Hg}$ that responded to fluid treatment or that required vasopressors), all-cause mortality during the hospital stay, and hospital stay (excluding non-survivors).

\section{Statistical Analysis}

Categorical variables are expressed as number and percent, and continuous variables as median and IQR. We conducted bivariate analysis to identify risk factors associated with $\mathrm{P}_{\mathrm{aO}_{2}} / \mathrm{F}_{\mathrm{IO}_{2}}<300 \mathrm{~mm} \mathrm{Hg}$. We analyzed continuous variables with the Student $t$ test or the Mann-Whitney $\mathrm{U}$ test, and categorical variables with the chi-square test (with the Yates correction when necessary) or the Fisher test. We also conducted multivariable logistic regression, with $\mathrm{P}_{\mathrm{aO}_{2}} / \mathrm{F}_{\mathrm{IO}_{2}}<300 \mathrm{~mm} \mathrm{Hg}$ as the dependent variable, and those variables with $P<.1$, along with those suspected of being related to hypoxemia development variables (COPD, age $>65 \mathrm{y}$, bilateral infiltrates on chest radiograph, acute renal failure, tobacco use, liver disease, and diabetes mellitus), as independent variables. The analysis was performed with statistics software (SPSS 15.0, SPSS, Chicago, Illinois). A $P$ value of $\leq .05$ was considered statistically significant.

\section{Results}

\section{Patients}

From 1,314 hospitalized patients with pneumonia, we excluded 119 patients with healthcare-associated pneumonia and 30 patients with immunosuppression, resulting in 1,165 patients with community-acquired pneumonia, and analyzed the 585 patients whose CURB-65 score was $\leq 1$ (Table 1). The mean $\pm \mathrm{SD}$ age was $54.7 \pm 17.8$ years (IQR 41-68 y), 365 (62\%) were men, 274 (51\%) had comorbidities, and 294 had hypoxemia (50\%) (Fig. 1).

\section{Risk Factors Associated With Hypoxemia}

Admission arterial blood sampling was performed during supplementary oxygen in a few patients: $32(11 \%)$ in the hypoxemic group, and $10(3 \%)$ in the non-hypoxemic group $(P<.001)$. The hypoxemic patients were significantly more likely to have COPD, age $>65$ years, dyspnea, tachypnea, cyanosis, bilateral chest radiograph involvement, hypoalbuminemia, blood urea nitrogen $>30 \mathrm{mg} / \mathrm{dL}$, and lower $\mathrm{pH}$.

An etiologic agent was found in 254 patients (43\%). There was a positive relationship between Streptococcus pneumoniae and hypoxemia (Table 2): bacteremic patients had hypoxemia more frequently (22 patients, 9\%) than non-bacteremic patients ( 9 patients, $4 \%, P=.048$ ).

\section{Outcomes}

The multivariable analysis found 3 risk factors that were independently associated with hypoxemia: bilateral chest radiograph involvement (odds ratio 2.8, 95\% CI 1.1-7.5), COPD (odds ratio $2.5,95 \%$ CI 1.4-4.3), and hypoalbuminemia (odds ratio $2.0,95 \%$ CI 1.1-3.5) (Table 3).

For the secondary outcomes, 33 patients $(6 \%)$ developed complications of pneumonia. The hypoxemic patients more frequently were admitted to the ICU (25 patients [9\%] vs 4 patients [1\%]) and had severe sepsis (11 patients [4\%] vs 2 patients [1\%]). And hospital stay was signifi- 
Table 1. Demographics, Comorbidities, Clinical and Radiological Variables, and Blood Chemistry Relative to $\mathrm{P}_{\mathrm{aO}_{2}} / \mathrm{F}_{\mathrm{IO}_{2}}$ in Patients With Mild Pneumonia*

\begin{tabular}{|c|c|c|c|}
\hline & \multicolumn{2}{|c|}{$\mathrm{P}_{\mathrm{aO}_{2}} / \mathrm{F}_{\mathrm{IO}_{2}}$} & \multirow[b]{2}{*}{$P$} \\
\hline & $\begin{array}{c}<300 \mathrm{~mm} \mathrm{Hg} \\
(n=294) \\
\text { no. }(\%)\end{array}$ & $\begin{array}{c}>300 \mathrm{~mm} \mathrm{Hg} \\
(n=291) \\
\text { no. }(\%)\end{array}$ & \\
\hline \multicolumn{4}{|l|}{ Demographics } \\
\hline Age $>65 y$ & $117(40)$ & $87(30)$ & .01 \\
\hline Male & $175(60)$ & $190(65)$ & .17 \\
\hline \multicolumn{4}{|l|}{ Comorbidities } \\
\hline Tobacco use & $93(32)$ & $106(37)$ & .44 \\
\hline Alcohol abuse & $47(16)$ & $32(11)$ & .08 \\
\hline Illicit drug abuse & $2(1)$ & $2(1)$ & $>.99$ \\
\hline Major comorbidities & $169(58)$ & $105(36)$ & .001 \\
\hline COPD & $94(32)$ & $50(17)$ & .002 \\
\hline Congestive heart failure & $30(10)$ & $19(7)$ & .11 \\
\hline Cerebrovascular disease & $16(5)$ & $12(4)$ & .46 \\
\hline Renal failure & $3(1)$ & $3(1)$ & $>.99$ \\
\hline Liver disease & $7(2)$ & $6(2)$ & .79 \\
\hline Diabetes mellitus & $49(17)$ & $34(12)$ & .08 \\
\hline \multicolumn{4}{|l|}{$\begin{array}{c}\text { Clinical and Radiological } \\
\text { Variables }\end{array}$} \\
\hline Dyspnea & $185(63)$ & $133(46)$ & .001 \\
\hline Confusion & $5(2)$ & $2(1)$ & .26 \\
\hline Cyanosis & $21(7)$ & $0(0)$ & .01 \\
\hline $\begin{array}{l}\text { Respiratory rate }>30 \\
\text { breaths/min }\end{array}$ & $13(5)$ & $3(1)$ & .01 \\
\hline $\begin{array}{l}\text { Bilateral chest radiographic } \\
\text { involvement }\end{array}$ & $33(11)$ & $15(5)$ & .007 \\
\hline \multicolumn{4}{|l|}{ Blood Chemistry } \\
\hline $\begin{array}{l}\text { Blood urea nitrogen } \\
\quad>30 \mathrm{mg} / \mathrm{dL}\end{array}$ & $182(63)$ & $146(51)$ & .00 \\
\hline Hypoalbuminemia & $55(35)$ & $35(22)$ & .01 \\
\hline $\mathrm{pH}<7.35$ & $10(3)$ & $2(1)$ & .02 \\
\hline $\mathrm{F}_{\mathrm{IO}_{2}}>0.21$ & $32(11)$ & $10(3)$ & .02 \\
\hline
\end{tabular}

cantly longer in the hypoxemic group $(10.8 \pm 11.2 \mathrm{~d}$ vs $8.9 \pm 6.6 \mathrm{~d}, P=.02)$.

Twelve patients $(2 \%)$ died, and mortality was significantly higher in the hypoxemic group (10 died [3\%] vs 2 died [1\%], $P=.02$ ) (Table 4).

\section{Discussion}

Approximately half of the patients (294 vs 291) had hypoxemic respiratory failure at admission. Bilateral alveolar infiltrates, history of COPD, and hypoalbuminemia were independently associated with hypoxemia, and hypoxemia was associated with longer hospital stay, greater probability of ICU admission, higher incidence of severe sepsis, and higher all-cause mortality. To our knowledge, this is first study to examine the impact of hypoxemia in

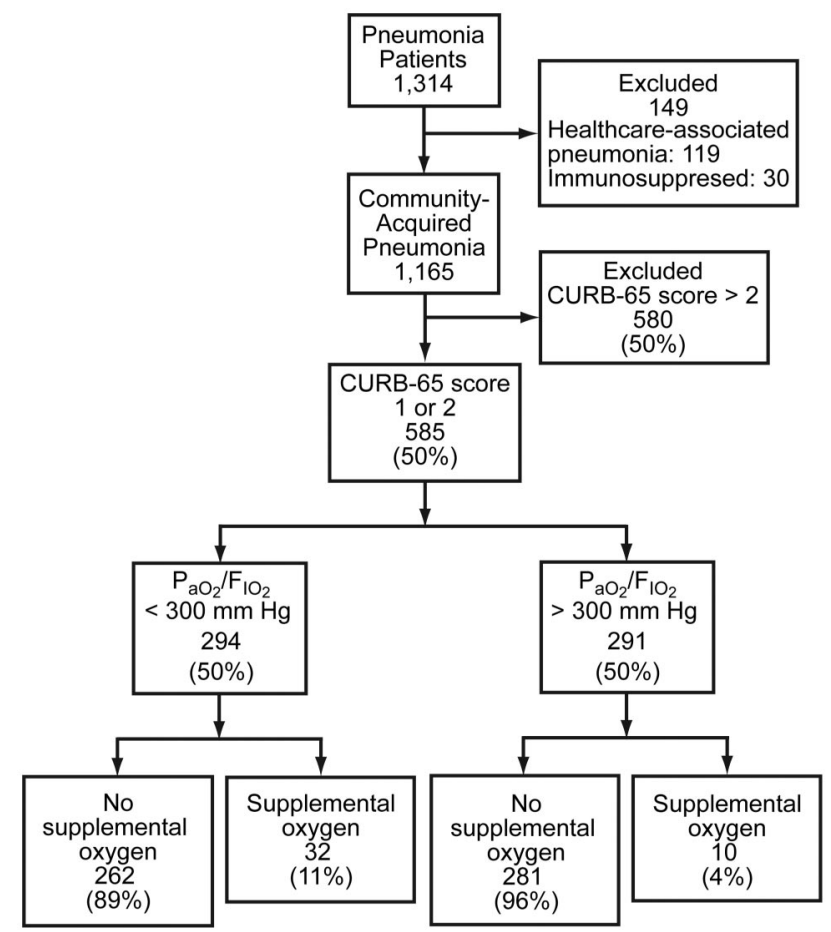

Fig. 1. Flow chart of patients with pneumonia, according to CURB-65 score.

Table 2. Microorganisms Relative to $\mathrm{P}_{\mathrm{aO}} / \mathrm{F}_{\mathrm{IO}_{2}}$ in Patients With Mild Pneumonia*

\begin{tabular}{lccc}
\hline \hline & \multicolumn{3}{c}{$\mathrm{P}_{\mathrm{aO}_{2}} / \mathrm{F}_{\mathrm{IO}_{2}}$} \\
\cline { 2 - 3 } & $\begin{array}{c}<300 \mathrm{~mm} \mathrm{Hg} \\
(n=294) \\
\text { no. }(\%)\end{array}$ & $\begin{array}{c}>300 \mathrm{~mm} \mathrm{Hg} \\
(n=291) \\
\text { no. }(\%)\end{array}$ & $P$ \\
\hline Streptococcus pneumoniae & $59(20)$ & $38(13)$ & .02 \\
Legionella pneumophila & $41(14)$ & $33(11)$ & .34 \\
Mycoplasma pneumoniae & $12(4)$ & $15(5)$ & .55 \\
Staphylococcus aureus & $3(1)$ & $1(<1)$ & .32 \\
Gram-negative bacilli & $3(1)$ & $4(1)$ & .7
\end{tabular}

* Mild pneumonia $=$ CURB-65 score of 0 or 1 .

patients with low-risk pneumonia per the CURB-65 score. Our results suggest that $\mathrm{P}_{\mathrm{aO}} / \mathrm{F}_{\mathrm{IO}_{2}}$, in addition to the CURB-65 score, can assist in identifying patients at risk of poor outcomes.

The involvement of pulmonary parenchyma in pneumonia represents a compromise of the target organ, which induces intrapulmonary shunt due to the alteration of alveolar ventilation. Hypoxemia in the context of pneumonia is an independent risk factor for mortality and determines treatment choices such as oxygen therapy, noninvasive mechanical ventilation, ICU admission, and invasive mechanical ventilation. ${ }^{13,16}$ However, limited data 
Table 3. Multivariable Analysis of Risk Factors for Hypoxemia in Patients With Mild Pneumonia*

\begin{tabular}{lccc}
\hline \hline & $\begin{array}{c}\text { Odds } \\
\text { Ratio }\end{array}$ & $95 \%$ CI & $P$ \\
\hline Bilateral radiographic involvement & 2.8 & $1.1-7.5$ & .04 \\
COPD & 2.5 & $1.4-4.3$ & .001 \\
Hypoalbuminemia & 2.0 & $1.1-3.5$ & .02 \\
* Mild pneumonia = CURB-65 score of 0 or 1. & & & \\
\hline
\end{tabular}

are available on patients with mild pneumonia, in contrast with the good evidence on patients with severe pneumonia.

Mortensen and colleagues assessed the causes of death in a cohort of 2,287 patients, ${ }^{17}$ and found that hypoxemia was significantly associated with pneumonia-related mortality (hazard ratio 1.99, 95\% CI 1.32-3.00). Using the Pneumonia Severity Index, Rosón et al prospectively examined the association between pneumonia severity, etiology, and the clinical outcome in patients with community-acquired pneumonia. ${ }^{12}$ There were 533 patients in their cohort, of whom $43 \%$ belonged to the low-risk categories. Sixty percent had hypoxemia, and those patients' risk of death was up to 5 times higher than the patient without hypoxemia. ${ }^{12}$ Myint et al, with a sample of 195 elderly patients with severe pneumonia (CURB-65 score $\geq 2$ in $97 \%$ of the patients), found that hypoxemia was the most significant predictor of 6-week mortality. ${ }^{18}$ Other severity pneumonia scoring systems, such as the one by España in 2006, considered hypoxemia $\left(\mathrm{P}_{\mathrm{aO}_{2}} / \mathrm{F}_{\mathrm{IO}_{2}}<250 \mathrm{~mm} \mathrm{Hg}\right.$ or $\mathrm{P}_{\mathrm{aO}_{2}}<54 \mathrm{~mm} \mathrm{Hg}$ ) one of the defining criteria for severe community-acquired pneumonia. They found that hypoxemia was associated with higher mortality and ICU admission. ${ }^{19}$ Buising et al, in a single-center study, analyzed predictors of severe pneumonia and found that oxygen saturation $\leq 90 \%$, was strongly associated with mortality (odds ratio 3.8, 95\% CI 1.7-8.5). However, in their study population over 56\% had severe pneumonia (Pneumonia Severity Index IV or V); on the other hand, they considered oxygen saturation regardless of the $\mathrm{F}_{\mathrm{IO}_{2}}{ }^{20}$
In our cohort with mild pneumonia, hypoxemia was associated with bilateral radiological involvement, hypoalbuminemia, and COPD. Bilateral or multi-lobar alveolar infiltrates predicted the failure of the early and late pneumonia treatment, and is included in several pneumonia severity scales. Bilateral infiltrates are associated with poor prognosis in patients with pneumonia. ${ }^{19,21}$ And there is a relationship between delayed resolution of pneumonia and the extent of the alveolar involvement on chest radiograph. ${ }^{22}$

COPD is not a determinant of higher pneumonia severity in the Pneumonia Severity Index or CURB-65 systems, but in clinical practice COPD is a factor in hospital admission in patients who are initially classified as having mild pneumonia. ${ }^{23,24}$ In patients with severe pneumonia, COPD is associated with an unfavorable clinical course, more complications, ICU admission, mechanical ventilation, and higher mortality than in those without COPD. ${ }^{17,25}$

We found that hypoalbuminemia was associated with hypoxemia in patients with mild pneumonia. Hypoalbuminemia is also associated with higher pneumonia severity, higher mortality, higher hospital costs, and longer recovery time. ${ }^{26-28}$ In the SMART-COP (low systolic blood pressure, multi-lobar chest radiography involvement, low albumin level, high respiratory rate, and tachycardia) assessment instrument, hypoalbuminemia is a factor in predicting the need for respiratory or vasopressors in patients with community-acquired pneumonia. ${ }^{29}$ Moreover, besides being an indicator of the nutritional state of the patient, hypoalbuminemia has been related to liver imbalance in protein synthesis at the cost of a higher production of acute phase reactants and pro-inflammatory cytokines. ${ }^{30}$ However, despite the association of that marker with hypoxemia in patients with mild pneumonia, its clinical use is limited.

Our study indicates that in patients with mild pneumonia, hypoxemic respiratory failure is associated with more complications and higher mortality than is expected with a CURB-65 score of 0 or 1 for the same state of pneumonia severity. ${ }^{10}$ CURB-65 makes no reference to hypoxemic respiratory failure as a severity factor. We suggest that

Table 4. Univariate Analysis of Clinical Outcomes in Patients With Mild Pneumonia*

\begin{tabular}{|c|c|c|c|c|c|}
\hline & \multicolumn{2}{|c|}{$\mathrm{P}_{\mathrm{aO}_{2}} / \mathrm{F}_{\mathrm{IO}_{2}}$} & \multirow{2}{*}{$\begin{array}{l}\text { Odds } \\
\text { Ratio }\end{array}$} & \multirow{2}{*}{$95 \% \mathrm{CI}$} & \multirow[b]{2}{*}{$P$} \\
\hline & $\begin{array}{c}<300 \mathrm{~mm} \mathrm{Hg} \\
\quad(n=294)\end{array}$ & $\begin{array}{c}>300 \mathrm{~mm} \mathrm{Hg} \\
\quad(n=291)\end{array}$ & & & \\
\hline Stay $($ mean $\pm S D$ d) & $10.8 \pm 11.2$ & $8.9 \pm 6.6$ & NA & NA & .02 \\
\hline ICU admission, no. (\%) & $25(9)$ & $4(1)$ & 6.6 & $2.3-19.4$ & .001 \\
\hline Septic shock, no. (\%) & $11(4)$ & $2(1)$ & 5.6 & $1.2-25.6$ & .01 \\
\hline Mechanical ventilation, no. $(\%)$ & $8(3)$ & $3(1)$ & 2.7 & $0.7-10.2$ & .13 \\
\hline Death, no. (\%) & $10(3)$ & $2(1)$ & 5.1 & $1.1-23.4$ & .02 \\
\hline
\end{tabular}




\section{Hypoxemia Adds to the CURB-65 Pneumonia Severity Score}

patients with mild pneumonia and hypoxemia should be carefully evaluated to identify patients who are more likely to have poor outcomes. The importance of oxygenation assessment was recently evaluated by Blot and colleagues. ${ }^{31}$ They found that early oxygenation assessment was associated with earlier antibiotic delivery and better ICU survival. Our findings reinforce the importance of oxygenation assessment in the initial evaluation of patients with mild community-acquired pneumonia. We think that oxygenation status assessment should be considered in all pneumonia patients, regardless of the pneumonia severity; pulse oximetry is a simple, cheap, and widely available method to assess oxygenation status. This approach may be especially useful for general practitioners taking care of patients with pneumonia in the community.

\section{Limitations}

Our study was performed in hospitalized patients, so our results could not be extended to patients with mild pneumonia who are not admitted to the hospital and in whom the incidence of hypoxemia would be expected to be lower. Our diagnosis of COPD was based on the Global Initiative for Chronic Obstructive Lung Disease definition, although for our analysis COPD was coded as a dichotomous variable (yes/no), without stratifying the patients according to their COPD severity. The decision making process to admit a patient to the ICU differed between centers, depending on the health resources and availability of ICU beds. Some cases of hypoxemic respiratory failure could be related to decompensation caused by a comorbidity (eg, COPD, heart failure) rather than to the parenchymal involvement of the pneumonia. Only 12 of our patients with CURB-65 scores of 0 or 1 died, so our study might have been underpowered to detect mortality differences between the groups.

\section{Conclusions}

Bilateral radiological involvement, hypoalbuminemia, and COPD are risk factors associated with hypoxemia in patients with mild pneumonia (CURB-65 score of 0 or 1). Patients with mild pneumonia and hypoxemia at hospital presentation have worse outcomes than non-hypoxemic patients, including higher ICU admission rate, more frequent severe sepsis, longer hospital stay, and higher mortality. Clinicians should evaluate for hypoxemia even in patients with mild pneumonia, to assist the CURB-65 score to identify patients at risk for complications and worse clinical outcomes.

\section{REFERENCES}

1. World Health Organization/WHO Statistical Information System (WHOSIS). WHO Mortality Database, 2005. http://www.who.int/ healthinfo/morttables/en/index.html. Accessed March 9, 2011.
2. Armstrong GL, Conn LA, Pinner RW. Trends in infectious disease mortality in the United States during the 20th century. JAMA 1999; 281(1):61-66

3. Feikin DR, Schuchat A, Kolczak M, Barrett NL, Harrison LH, Lefkowitz L, et al. Mortality from invasive pneumococcal pneumonia in the era of antibiotic resistance, 1995-1997. Am J Public Health 2000;90(2):223-229.

4. Macfarlane JT, Boswell T, Douglas G, Finch R, Holmes W, Honeybourne $\mathrm{D}$, et al. BTS guidelines for the management of community acquired pneumonia in adults. Thorax 2001;56(Suppl 4):iv1-iv64.

5. Macfarlane JT, Boldy D. 2004 update of BTS pneumonia guidelines: what's new? Thorax 2004;59(5):364-366.

6. Mandell LA, Wunderink RG, Anzueto A, Bartlett JG, Campbell GD, Dean NC, et al. Infectious Diseases Society of America/American Thoracic Society consensus guidelines on the management of community-acquired pneumonia in adults. Clin Infect Dis 2007;44(Supp1 2):S27-S72.

7. Ewig S, Welte T. CRB-65 for the assessment of pneumonia severity: who could ask for more? (editorial). Thorax 2008;63(8):665-666.

8. Fine MJ, Auble TE, Yealy DM, Hanusa BH, Weissfeld LA, Singer $\mathrm{DE}$, et al. A prediction rule to identify low-risk patients with community-acquired pneumonia. N Engl J Med 1997;336(4):243-250.

9. Lim WS, Lewis S, Macfarlane JT. Severity prediction rules in community-acquired pneumonia: a validation study. Thorax 2000;55(3): 219-223.

10. Lim WS, van der Eerden MM, Laing R, Boersma WG, Karalus N, Town GI, et al. Defining community acquired pneumonia severity on presentation to hospital: an international derivation and validation study. Thorax 2003;58(5):377-382.

11. Man SY, Lee N, Ip M, Antonio GE, Chau SS, Mak P, Graham CA, et al. Prospective comparison of three predictive rules for assessing severity of community-acquired pneumonia in Hong Kong. Thorax 2007;62(4):348-353.

12. Rosón B, Carratalà J, Dorca J, Casanova A, Manresa F, Gudiol F. Etiology, reasons for hospitalization, risk classes, and outcomes of community-acquired pneumonia in patients hospitalized on the basis of conventional admission criteria. Clin Infect Dis 2001;33(2):158165.

13. Rabe KF, Hurd S, Anzueto A, Barnes PJ, Buist SA, Calverley P, et al; Global Initiative for Chronic Obstructive Lung Disease. Global strategy for the diagnosis, management, and prevention of chronic obstructive pulmonary disease: GOLD executive summary. Am J Respir Crit Care Med 2007;176(6):532-555.

14. Bowton DL, Scuderi PE, Haponik EF. The incidence and effect on outcome of hypoxemia in hospitalized medical patients. Am J Med 1994(1):97:38-46.

15. Karbing DS, Kjaergaard S, Smith BW, Espersen K, Allerød C, Andreassen $\mathrm{S}$, et al. Variation in the $\mathrm{P}_{\mathrm{aO} 2} / \mathrm{F}_{\mathrm{IO} 2}$ ratio with $\mathrm{F}_{\mathrm{IO} 2}$ : mathematical and experimental description, and clinical relevance. Crit Care 2007;11(6):R118.

16. Ferrer M, Esquinas A, Leon M, Gonzalez G, Alarcon A, Torres A. Noninvasive ventilation in severe hypoxemic respiratory failure: a randomized clinical trial. Am J Respir Crit Care Med 2003;168(12): 1438-1444.

17. Mortensen EM, Coley CM, Singer DE, Marrie TJ, Obrosky DS, Kapoor WN, Fine MJ. Causes of death for patients with communityacquired pneumonia. Arch Intern Med 2002;162(9):1059-1064.

18. Myint PK, Kamath AV, Vowler SL, Maisey DN, Harrison BD. Severity assessment criteria recommended by the British Thoracic Society (BTS) for community-acquired pneumonia (CAP) and older patients. Should SOAR (systolic blood pressure, oxygenation, age and respiratory rate) criteria be used in older people? A compilation study of two prospective cohorts. Age Ageing 2006;35(3):286-291. 


\section{Hypoxemia Adds to the CURB-65 Pneumonia Severity Score}

19. España PP, Capelastegui A, Gorordo I, Esteban C, Oribe M, Ortega $\mathrm{M}$, et al. Development and validation of a clinical prediction rule for severe community-acquired pneumonia. Am J Respir Crit Care Med 2006;174(11):1249-1256.

20. Busing KL, Thursky KA, Black JF, MacGregor L, Street AC, Kennedy MP, Brown GV. Identifying severe community-acquired pneumonia in the emergency department: a simple clinical prediction tool. Emerg Med Australas 2007;19(5):418-426.

21. Menéndez R, Torres A, Zalacaín R, Aspa J, Martín-Villasclaras JJ, Borderías L, et al.; Neumofail Group. Risk factors of treatment failure in community acquired pneumonia: implications for disease outcome. Thorax 2004;59(11):960-965.

22. Bruns AH, Oosterheert JJ, Prokop M, Lammers JW, Hak E, Hoepelman AI. Patterns of resolution of chest radiograph abnormalities in adults hospitalized with severe community-acquired pneumonia. Clin Infect Dis 2007;45(8):983-991.

23. Marrie TJ, Marrie MD, Huang JQ. Low-risk patients admitted with community-acquired pneumonia. Am J Med 2005;118(12):13571363.

24. Restrepo MI, Mortensen EM, Pugh JA, Anzueto A. COPD is associated with increased mortality in patients with community-acquired pneumonia. Eur Respir J 2006;28(2):346-351.

25. Rello J, Rodriguez A, Torres A, Roig J, Sole-Violan J, GarnachoMontero J, et al. Implications of COPD in patients admitted to the intensive care unit by community-acquired pneumonia. Eur Respir J 2006;27(6): 1210-1216.

26. Reyes S, Martinez R, Vallés JM, Cases E, Menendez R. Determinants of hospital costs in community-acquired pneumonia. Eur Respir J 2008;31(5):1061-1067.

27. Menéndez R, Cremades MJ, Martínez-Moragón E, Soler Reyes S, Perpiñá M. Duration of length of stay in pneumonia: influence of clinical factors and hospital type. Eur Respir J 2003;22(4):643-648.

28. Sankaran RT, Mattana J, Pollack S, Bhat P, Ahuja T, Patel A, Singhal PC. Laboratory abnormalities in patients with bacterial pneumonia. Chest 1997;111(3):595-600.

29. Charles PG, Wolfe R, Whitby M, Fine MJ, Fuller AJ, Stirling R, et al; Australian Community-Acquired Pneumonia Study Collaboration. SMART-COP: a tool for predicting the need for intensive respiratory or vasopressor support in community-acquired pneumonia Clin Infect Dis 2008;47(3):375-384.

30. Hedlund JU, Hansson LO, Ortqvist AB. Hypoalbuminemia in hospitalized patients with community-acquired pneumonia. Arch Intern Med 1995;155(13):1438-1442.

31. Blot SI, Rodriguez A, Solé-Violán J, Blanquer J, Almirall J, Rello $\mathrm{J}$; Community-Acquired Pneumonia Intensive Care Units (CAPUCI) Study Investigators. Effects of delayed oxygenation assessment on time to antibiotic delivery and mortality in patients with severe community-acquired pneumonia. Crit Care Med 2007; 35(11):2509-2514. 